7th International Symposium on Superalloy 718 and Derivatives Edited by: E.A. Ott, J.R. Groh, A. Banik, I. Dempster, T.P. Gabb, R. Helmink, X. Liu, A. Mitchell, G.P. Sjöberg, and A. Wusatowska-Sarnek TMS (The Minerals, Metals \& Materials Society), 2010

\title{
EFFECT OF PHOSPHORUS ON MICROSTRUCTURE AND \\ MECHANICAL PROPERTIES OF IN718 ALLOY AFTER HOT \\ CORROSION AND OXIDATION
}

\author{
Z. Q. Hu, X. M. Lou, W. R. Sun, L. X. Yu, S. L. Yang, W. H. Zhang \\ Institute of Metal Research, Chinese Academy of Sciences \\ 72 Wenhua Road, Shenyang, 110016, P. R. China
}

Keywords: Phosphorus, mechanical properties, hot corrosion, oxidation

\begin{abstract}
In this paper, the IN718 alloys added with various phosphorus concentration underwent hot corrosion in the mixed salts of $75 \% \mathrm{Na}_{2} \mathrm{SO}_{4}$ and $25 \% \mathrm{NaCl}$ at $650{ }^{\circ} \mathrm{C}$ and oxidation in air at $650{ }^{\circ} \mathrm{C}$, and then the microstructure and properties of the alloys were characterized. No difference was found of the tensile properties of IN718 alloy after soaking at $100 \mathrm{~h}$ in air and in mixed salt. However, phosphorus exhibits an effect to inhibit the ingression of sulfur along the grain boundaries. The thermal exposure in air at $650{ }^{\circ} \mathrm{C}$ makes no differences on the tensile properties, but reduces the total term of the primary and secondary creep stages of IN718 alloy, while the alloy added with $0.019 \%$ phosphorus exhibits the same creep curves with and without thermal exposure. The interaction mechanism between phosphorus and hot corrosion and oxidation is discussed briefly in the paper.
\end{abstract}

\section{Introduction}

IN718 alloy, as one of the most important nickel-based superalloys, is widely used for high temperature parts of aircraft turbines and steam turbines. With various compositions, IN718 alloy is mainly strengthened by the precipitation of $\gamma^{\prime \prime}-\mathrm{Ni}_{3} \mathrm{Nb}\left(\mathrm{DO}_{22}\right.$ structure $)$ and $\gamma^{\prime}-\mathrm{Ni}_{3}(\mathrm{Al}, \mathrm{Ti})\left(\mathrm{L}_{2}\right.$ structure) phases. Recently, it has been found that phosphorus greatly improved the stress rupture and creep properties of IN718 alloy [1-3]. The researches related to the mechanism of this phenomenon were mainly focused on the influence of phosphorus on the grain boundaries because it has a strong tendency to be highly concentrated there. It has also been proposed that when phosphorus segregates to the grain boundaries, it can inhibit the diffusion of oxygen atoms along the grain boundaries [4]. 
Hot-corrosion is the accelerated oxidation of a material at an elevated temperature induced by a thin film of fused salt deposit, such as fused $\mathrm{Na}_{2} \mathrm{SO}_{4}$. The hot corrosion of Ni-base superalloys is often characterized by the appearance of sulfides in the metal substrate beneath the outer oxide scale. Studies by Goebel and Pettit showed that sulfide formation indeed resulted from the reaction of the metallic substrate with a thin film of fused salt of sodium sulfate base [5]. During hot corrosion, sulfur prefers to diffuse along grain boundaries leading to the formation of metallic sulfides [6]. There are two purposes for the present paper. The first is to clarify the hot corrosion behavior of IN718, and the second is to identify the effect of phosphorus on grain boundary sulfidation.

\section{Experimental}

Two test alloys of $10 \mathrm{~kg}$ ingot, manufactured from one master ingot of IN718 alloy, were prepared by vacuum induction melting (VIM). The chemical composition of the master alloy is as following (wt.\%), Cr 19.0, Fe 18.2, Mo 3.09, Nb 5.50, Al 0.49, Ti 1.05, S 0.003, B <0.003, C 0.025 , Ni bal. The phosphorus level of the two alloys are: $<0.001$ wt.\% (alloy 1), 0.019 wt.\% (alloy 2). Following homogenization treatment, the ingots were forged and rolled to round bars of $16 \mathrm{~mm}$ in diameter within the temperature range of $1100 \square-950 \square$. After direct aging (DA) heat treatment (720 $\square$ for 8 hours, followed by furnace cooling to $620 \square$ for 2 hours, and held at this temperature for 8 hours, then air cooled), the bars were cut into various specimens for hot corrosion, oxidation and creep tests. Specially, one specimen of each alloy was chosen to be aged

at $750{ }^{\circ} \mathrm{C}$ for an additional $240 \mathrm{~h}$.

For the hot corrosion and oxidation test, the size of the specimens was $10 \mathrm{~mm} \times 3.5 \mathrm{~mm} \times 3.5 \mathrm{~mm}$.

All faces were ground with $\mathrm{SiC}$ abrasive paper down to 1200-grit in small steps, and polished with diamond paste. Finally, the specimens were ultrasonically cleansed in acetone and then in ethanol. Hot corrosion tests were performed by immersing the specimens completely in a fused salt mixture of $\mathrm{Na}_{2} \mathrm{SO}_{4}(75$ wt. \%) and $\mathrm{NaCl}$ (25 wt.\%) contained in corundum crucibles, and then heating the crucibles in air at $680 \square$ for times ranging from $5 \mathrm{~min}$ to $200 \mathrm{~h}$. In order to characterize the surface oxidation effect, a sample was also oxidized at $650{ }^{\circ} \mathrm{C}$ for $100 \mathrm{~h}$. The three-dimensional image of the oxidized sample was analyzed by Olympus laser scanning confocal microscope (LSCM) LEXT $^{\mathrm{TM}}$ OLS3000. The surfaces of the scales were subsequently examined by scanning electron microscopy (SEM) equipped with an energy dispersive spectrum (EDS) analyzer. The phases of the scales were determined by X-ray diffraction (XRD). Specimens were electroless nickel plated and then mounted in epoxy resin. The cross-sections, both unetched and etched by a $\mathrm{Cu}_{2} \mathrm{SO}_{4}$ corrosive etchant, were observed by $\mathrm{SEM}$ and the elemental distribution of the scale layers was analyzed by EDS.

Specially, to analyze the effect of phosphorus on oxidation of IN718 alloy, the rolled bars with various phosphorus concentrations were also underwent the two different treatments. For the first 
group, the bars were DA treated plus additionally aged at $650{ }^{\circ} \mathrm{C}$ for $300 \mathrm{~h}$, then machined for creep test. For the other group, the bars were firstly machined to the shape ready for creep test, then DA treated plus additionally aged at $650{ }^{\circ} \mathrm{C}$ for $300 \mathrm{~h}$.

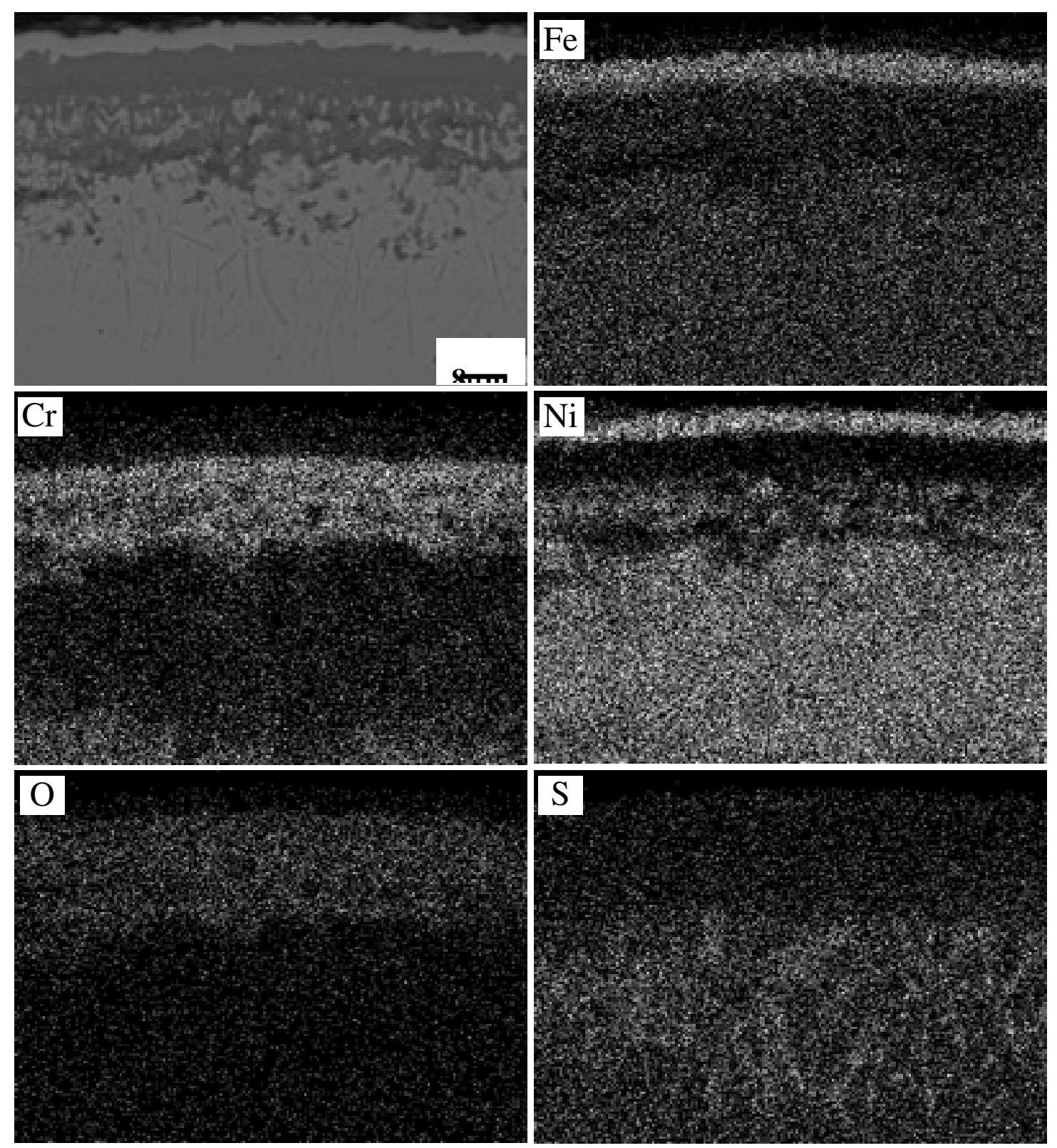

Fig.1 Microstructure and EDS X-ray maps of the elements at the scale of alloy 1 formed by hot corrosion at $680^{\circ} \mathrm{C}$ for $200 \mathrm{~h}$. 

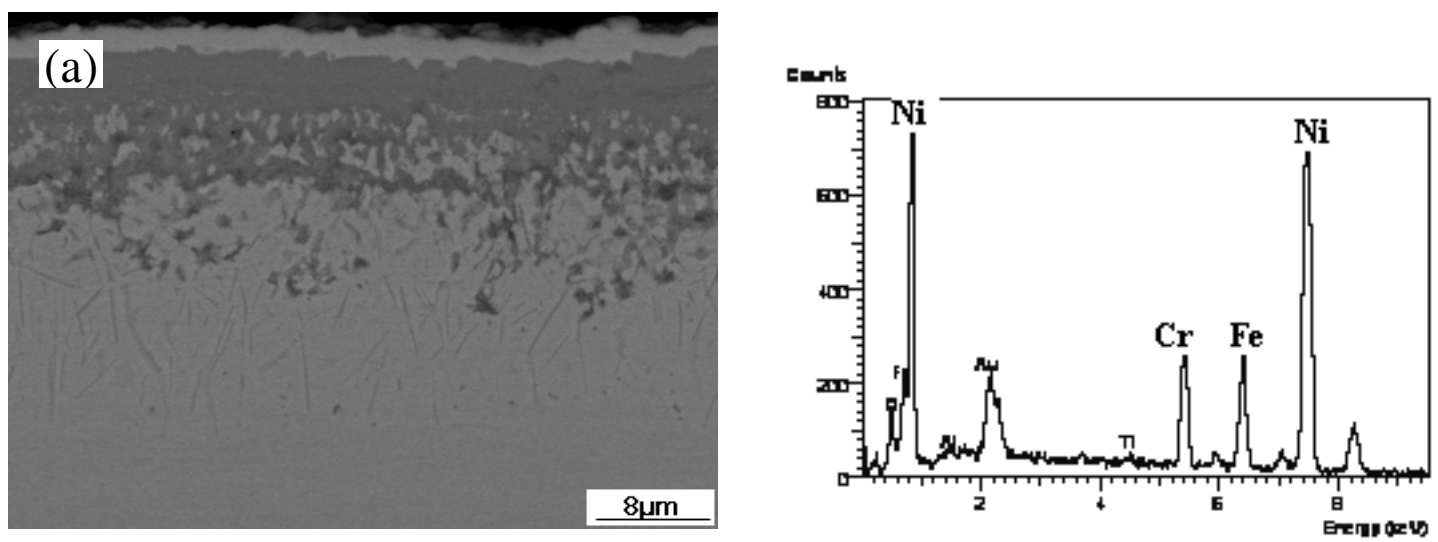

(b)

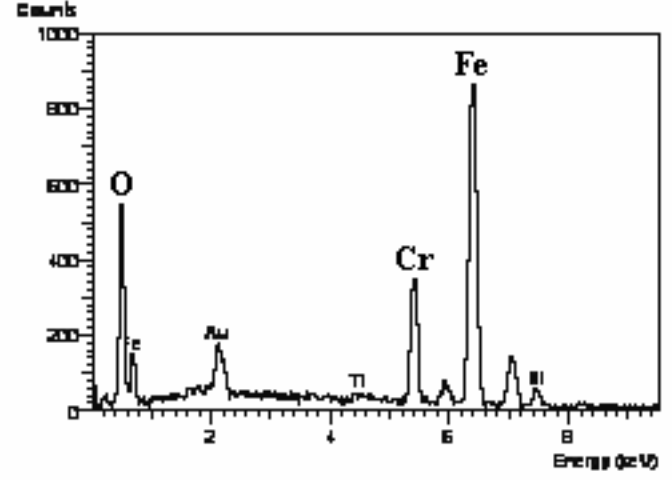

(c)

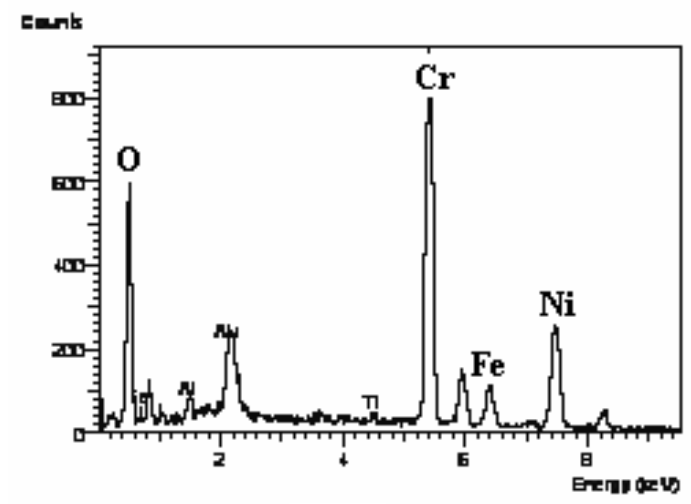

(e)

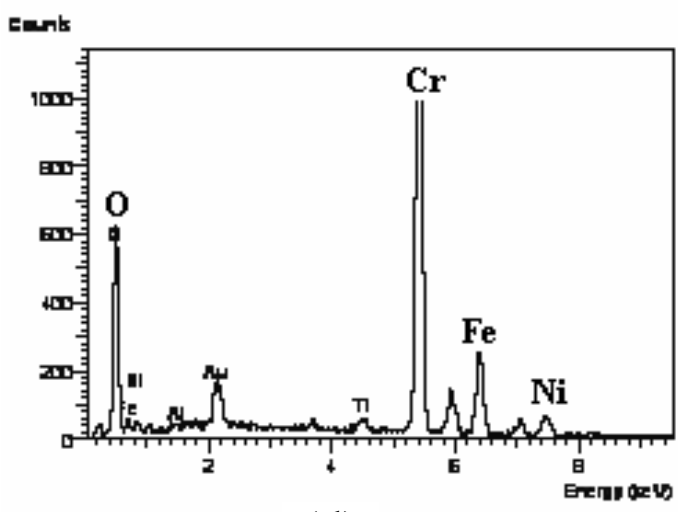

(d)

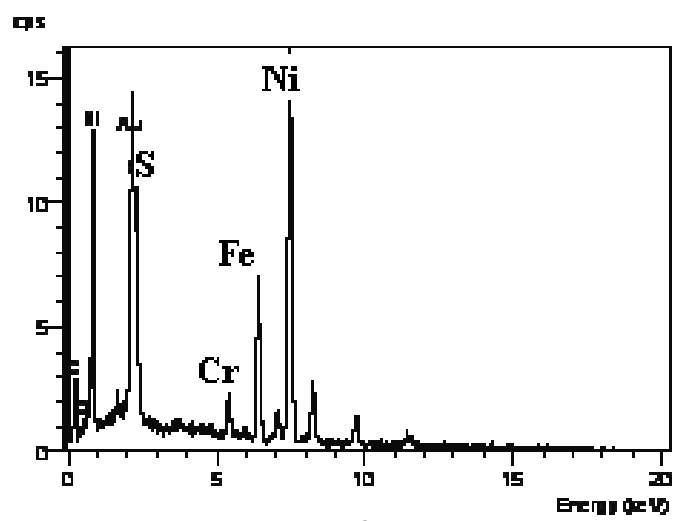

(f)

Fig. 2 SEM image of the multi-layered scale (a) and EDS results of each phase in the scale of alloy 1 formed by hot corrosion at $680{ }^{\circ} \mathrm{C}$ for $200 \mathrm{~h}$ : (b) Light phase in the scale near the scale/substrate interface, (c) the external layer, (d) the second layer, (e) the dark phase in the third layer and (f) the needle like phase in the subscale. 


\section{Hot corrosion}

\section{Results}

The melting point of the mixed salt of $\mathrm{Na}_{2} \mathrm{SO}_{4}(75$ wt. $\%$ ) and $\mathrm{NaCl}(25$ wt.\%) is lower than $680 \square$, so it was totally melted during the hot corrosion test. Fig.1 shows the cross-section morphology and the EDS X-ray maps of the scale formed on the surface of the specimen of alloy 1 after hot corrosion treated at $680 \square$ for $200 \mathrm{~h}$. A multi-layered structure can be observed based on the distribution of elements. The corrosion scale consisted of three different layers: an external (dark) oxide layer, a discontinuous layer consisting of dark phases and light phases, and subscale layer between the second layer and the substrate. The results of alloy 2 were the same as the above stated results for the sample of alloy 1 .

Fig. 2 shows the typical SEM image of the corrosion scale and the EDS results from different locations in the corrosion scale. As shown in Fig. 2(b), all the light phases in various locations had a similar composition, containing mainly $\mathrm{Ni}$. The external oxide layer was approximately 2 $\mu \mathrm{m}$, and contained mainly $\mathrm{Fe}, \mathrm{Cr}$ and $\mathrm{O}$. The amount of $\mathrm{Fe}$ was more than $\mathrm{Cr}$, according to the EDS result shown in Fig. 2(c). The second discontinuous layer was approximately $4 \mu \mathrm{m}$ thick, and consisted of some light phases and dark phases. The dark phases were the oxides of $\mathrm{Cr}$ and $\mathrm{Ni}$, based on the EDS result shown in Fig. 2(d). An independent continuous NiO layer did not exist in the scale. Besides the light phase, which was mainly composed of $\mathrm{Ni}$, some dark needle-like phases could also be observed in the subscale layer. Sulfur was detected in this phase as shown in Fig. 2(f), so this needle-like phase was most likely nickel sulfide. The X-ray diffraction (XRD) examination was also employed to identify the corrosion products and the XRD results have characterized the peaks of $\mathrm{Cr}_{2} \mathrm{O}_{3}, \mathrm{FeCr}_{2} \mathrm{O}_{4}, \mathrm{Fe}_{2} \mathrm{O}_{3}, \mathrm{NiO}$ and $\mathrm{Ni}_{3} \mathrm{~S}_{2}$. Combining all the EDS results of elemental distribution with the XRD results, the major oxides formed in the scale were identified as $\mathrm{Fe}_{2} \mathrm{O}_{3}, \mathrm{FeCr}_{2} \mathrm{O}_{4}, \mathrm{Cr}_{2} \mathrm{O}_{3}$, and $\mathrm{NiO}$, and the sulfide was $\mathrm{Ni}_{3} \mathrm{~S}_{2}$. No other types of sulfide were found.

Fig. 3 shows the cross-sectional microstructure of the subscale and substrate of each alloy etched by the $\mathrm{Cu}_{2} \mathrm{SO}_{4}$ solution. A light phase precipitated along the grain boundaries constantly appeared adjacent to the subscale in the alloy 1, as shown in Fig. 3(a). As no such white phase was found in the grain boundaries far away from the interface, so these white phases in front of the interface should not be the residual high temperature phases and they are more likely to be the reaction product. From Fig. 2, it shows the needle like sulfide was preferentially formed in front of the subscale-substrate interface. Based on the fact that it was connected with the subscale, the light phase was identified as nickel sulfide, formed by the sulfur diffusion along the grain boundaries. It should be mentioned that the penetration depth of sulfur in front of the subscale-substrate interface was very limited. Contrary to alloy 1 , the light phase was not present along the grain boundaries of the alloy 2 (see Fig.3b). This result indicates that P can inhibit the sulfidation of grain boundaries of IN718 alloy during hot corrosion treatment. 

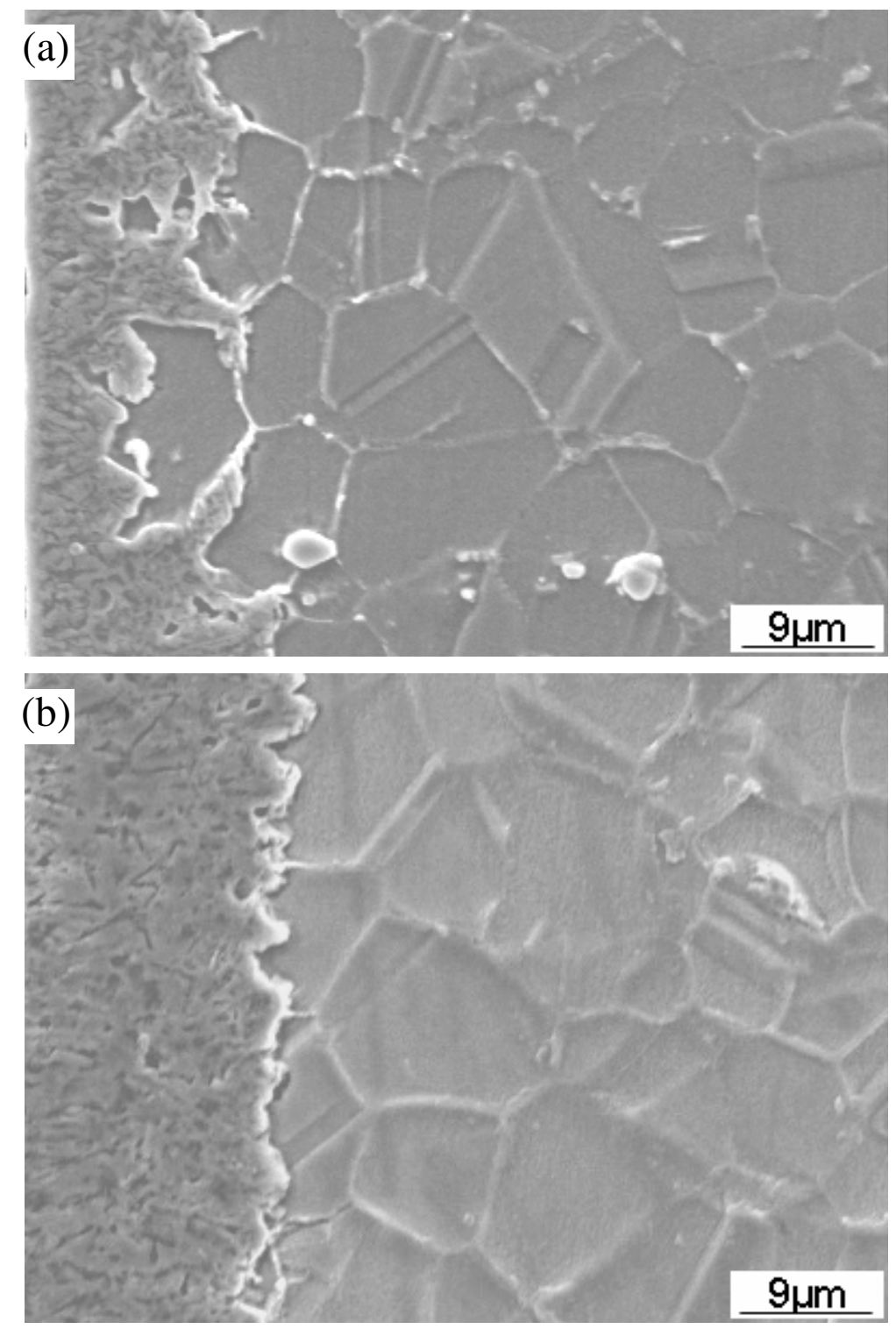

Fig.3 Effect of phosphorus on the grain boundary corrosion of IN718 alloy: (a) alloy 1 and (b) alloy 2

In order to clarify the role of the main strengthening precipitation of the alloy, $\gamma^{\prime \prime}$, an extra heat treatment, aging at $750 \square$ for $240 \mathrm{~h}$, was adopted. Following that, the specimen underwent hot corrosion for $100 \mathrm{~h}$. The multi-layered structure similar to Fig. 1 was also present in the scale of the specimen, and will not be presented again. Fig. 4 shows the cross-sectional microstructure of the subscale and substrate etched by the $\mathrm{Cu}_{2} \mathrm{SO}_{4}$ solution. Because of the existence of $\delta$-phase, the sulfide which appears clearly in Fig. 3(a) was not observed. No free-precipitation zone existed ahead of the subscale. This result, combined with the fact that nickel sulfide was surrounded by nickel, indicated that the sulfide was formed by the diffusion of S into the alloy, not the outward diffusion of $\mathrm{Ni}$. 


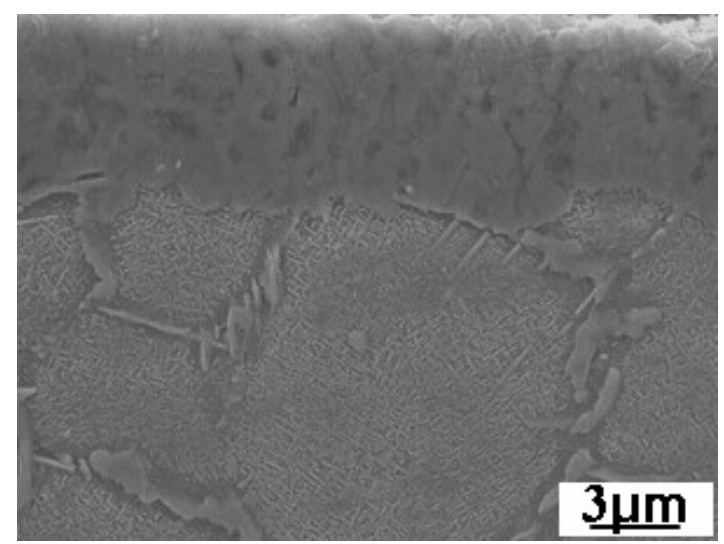

Fig. 4 Microstructure of alloy 1 aged at $750^{\circ} \mathrm{C}$ for $240 \mathrm{~h}$ and hot corrosion tested at $680^{\circ} \mathrm{C}$ for $100 \mathrm{~h}$.
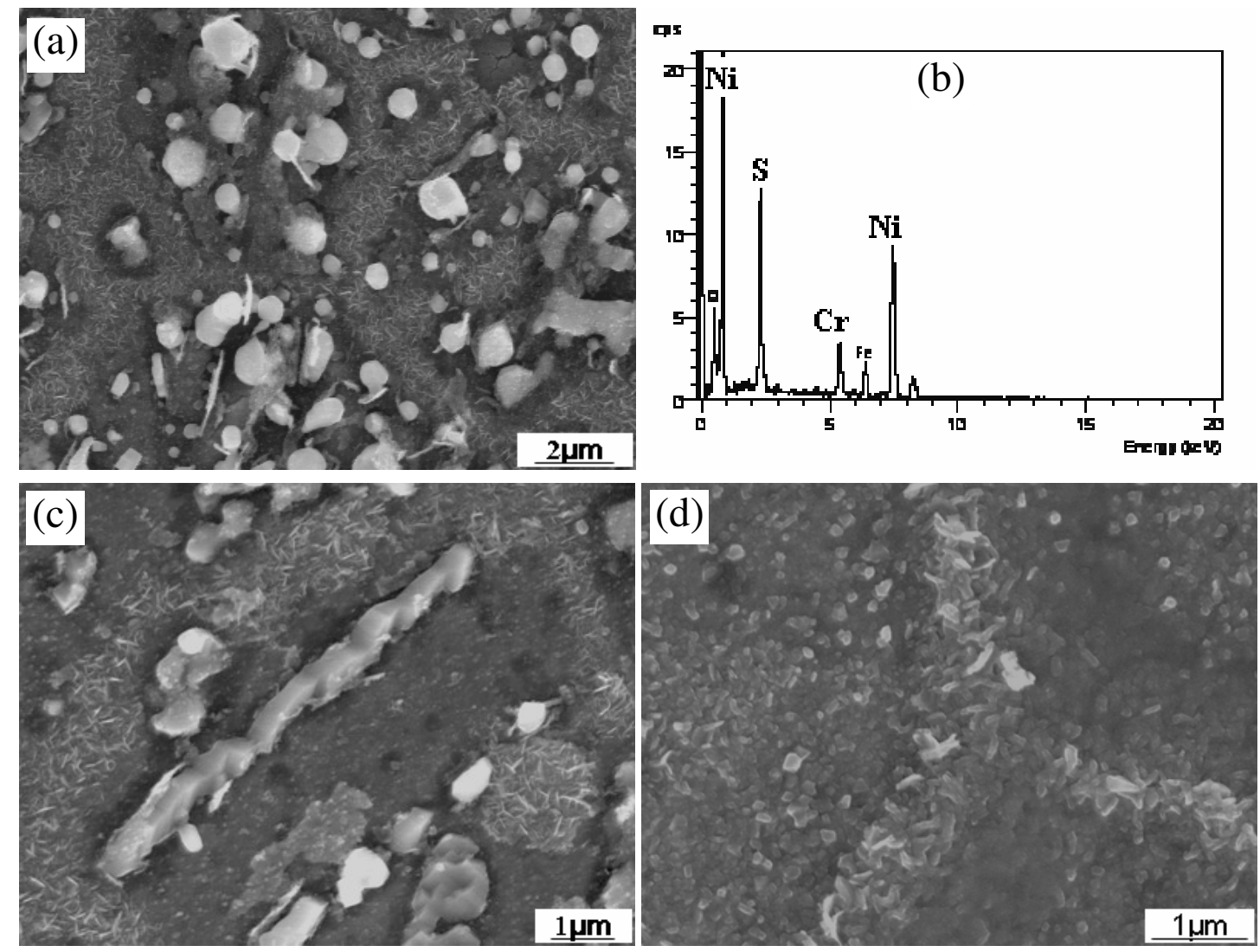

Fig.5 Formation of hot corrosion products at the initial stage of alloy 1: (a) and (b)

Microstructure and EDS of the scale formed at the grain boundary ( $\left.680{ }^{\circ} \mathrm{C} \times 5 \mathrm{~min}\right)$; (c)

Microstructure of the scale formed at the twins ( $\left.680{ }^{\circ} \mathrm{C} \times 5 \mathrm{~min}\right)$; (d) Microstructure of the scale formed at the twins $\left(680^{\circ} \mathrm{C} \times 15 \mathrm{~min}\right)$. 
Fig. 5 shows the SEM micrographs of the surfaces of scales grown in the initial stage of hot corrosion, and the EDS spectrum is also included. Two different features were observed when the specimen underwent hot corrosion for 5 min and 15 min respectively. As shown in Fig. 5(a), some needle like phases and nodules were developed after hot corrosion treatment for $5 \mathrm{~min}$. The needle like phase was formed along the grain boundary and could be identified as $\mathrm{Cr}_{2} \mathrm{O}_{3}$. Sulfur and a large amount of Ni were detected in the nodule through EDS (Refer to Fig. 5(b)). This phase could be proposed as the eutectic $\mathrm{Ni}^{-} \mathrm{Ni}_{3} \mathrm{~S}_{2}$ which will be discussed in the following discussion section. Along the twin-boundary another light phase was also observed after hot corrosion treatment for 5 min (Fig. 5(c)). Because the width of this phase was less than $1 \mu \mathrm{m}$, a valid EDS result could not be achieved. Based on the proposition made on the eutectic $\mathrm{Ni}^{-} \mathrm{Ni}_{3} \mathrm{~S}_{2}$, this light phase might be identified as $\mathrm{Ni}_{3} \mathrm{~S}_{2}$. In contrast to the surface morphology formed after hot corrosion treatment for $5 \mathrm{~min}$, no nodules were observed after hot corrosion treatment for 15min, and the size of the needle like phase in Fig. 5(d) was a little larger than that shown in Fig. 5(a). Besides the needle-like oxide, the remaining part of the surface was covered with spinel oxide.
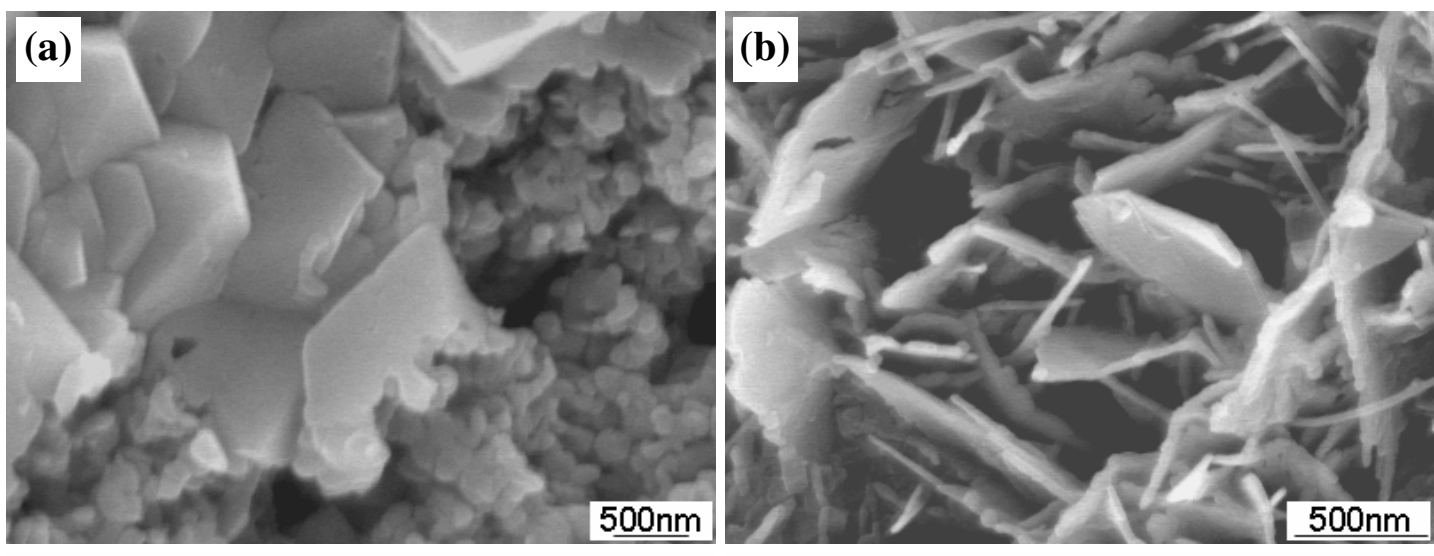

m5

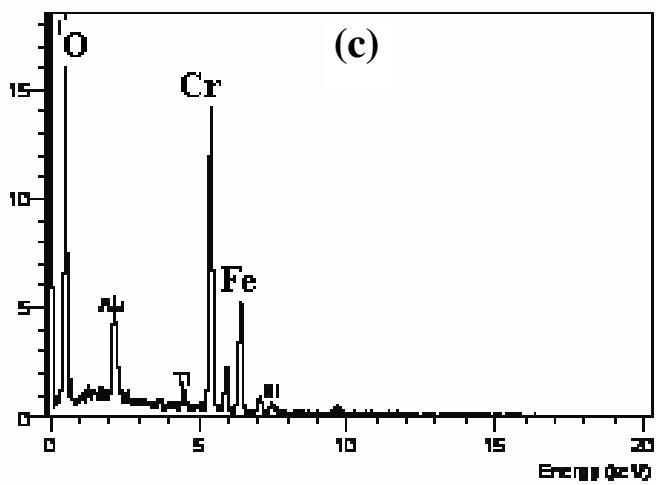

45

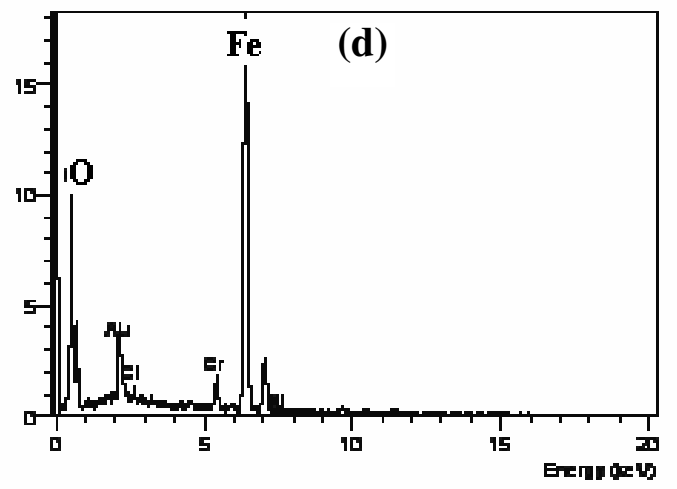



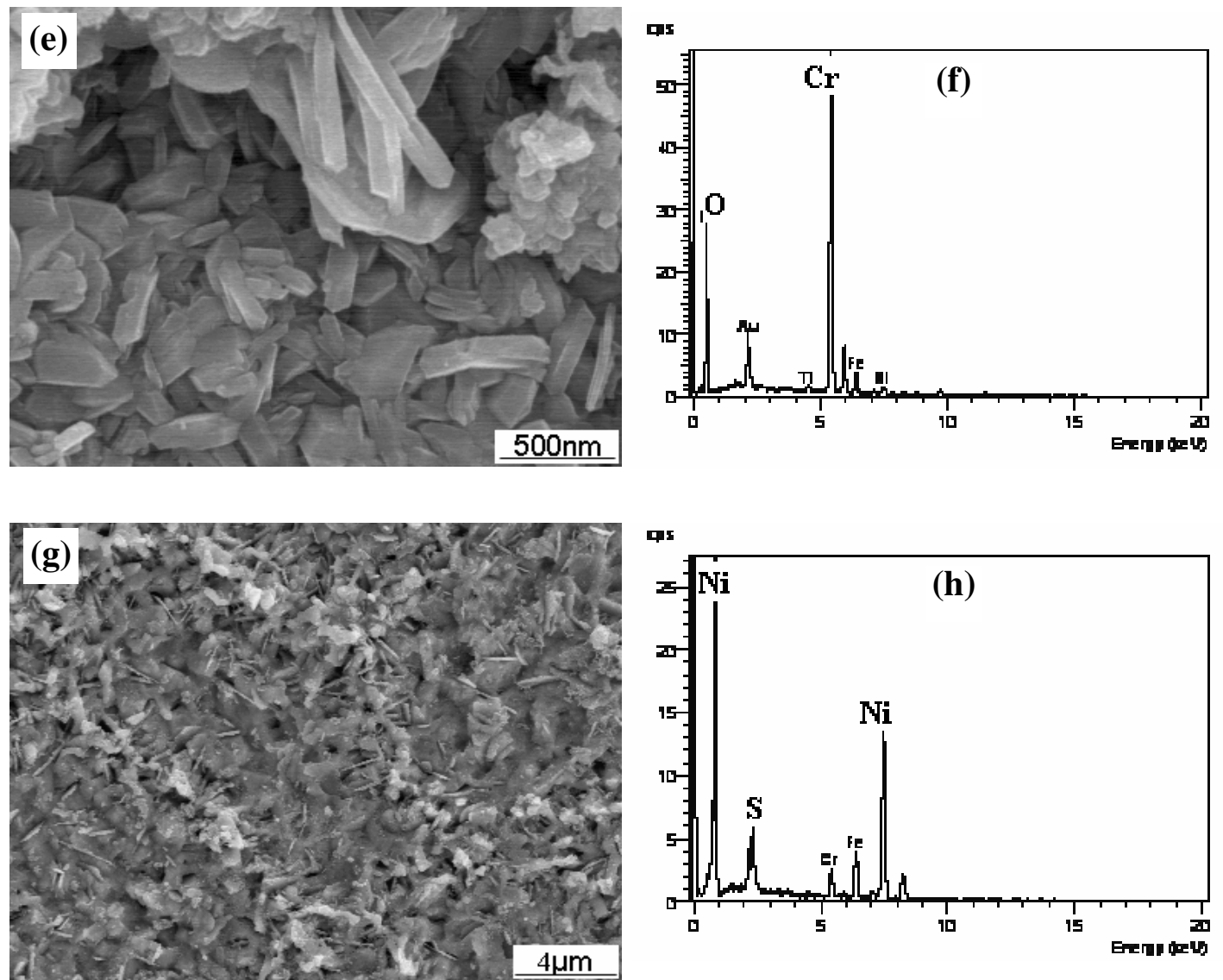

Fig. 6 SEM images (a, c and e) showing morphologies and EDS spectra (b, $d$ and $f$ ) of phases on the surface of alloy 1 after hot corrosion treated at $680^{\circ} \mathrm{C}$ for $100 \mathrm{~h}$.

Fig. 6 shows the morphologies and the EDS spectra of different layers in the scale formed after hot corrosion treatment for $100 \mathrm{~h}$. Two phases with different microstructure were observed in the external surface of the specimen as shown in Fig. 6(a) and Fig. 6(b). The EDS results show that the first spinel phase contains mainly $\mathrm{Fe}, \mathrm{Cr}$ and $\mathrm{O}$, as shown in Fig. 6(c) and the second flake-like phase was significantly rich in $\mathrm{Fe}$ and $\mathrm{O}$, as shown in Fig. 6(d). Combining the $\mathrm{X}$-ray diffraction results with the EDS data indicates that the first oxide was $\mathrm{FeCr}_{2} \mathrm{O}_{4}$, and the second was $\mathrm{Fe}_{2} \mathrm{O}_{3}$. Fig. 6(e) shows a rod-like microstructure of the phase in the second oxide layer. High concentrations of $\mathrm{Cr}$ and $\mathrm{O}$ were detected in the phase as shown in Fig. 6(f) and $\mathrm{Cr}_{2} \mathrm{O}_{3}$ was confirmed as the result. The morphology of the subscale was revealed in Fig. 6(g), after the external oxide layers were removed by high speed flowing water. The grain boundaries were clearly visible, and appeared lighter than the other areas. Inside the grains, the presence of some flake-like phases could be observed. Viewed along with the black needle-like phase shown in Fig. 1 , which is located in the subscale, it could be concluded that they are both $\mathrm{Ni}_{3} \mathrm{~S}_{2}$ but are shown in different sections. Special attention should be paid to the fact that the elements in the vicinity of $\mathrm{Ni}_{3} \mathrm{~S}_{2}$ were mainly $\mathrm{Ni}$, with a little $\mathrm{Fe}$, but the amount of $\mathrm{Cr}$ was very limited( as shown in Fig. 6(h)), contrary to the concentration of $\mathrm{Fe}$ and $\mathrm{Cr}$ in the base alloy. This result signifies that the 
reaction between $\mathrm{Ni}$ and $\mathrm{S}$ was exclusive and repelled other metallic elements.

Some additional results also need to be presented. The residual salt was dissolved in water after the $200 \mathrm{~h}$ hot corrosion test. After being examined by an acid-base indicator, the water proved to be basic solution. The PH scale was only in between 7 and 8, indicating the existence of $\mathrm{O}^{2-}$ in the salt but with very limited amounts. Moreover, no yellow chromate in the residual salt was found and no other metallic elements can be detected in the residual salt except Na. However, some dark substance was present at the interface between the mixed salt and the crucible. Two possibilities are proposed to explain the accumulation of this dark substance: first, this was formed because of some impurities contained in the experimental environment. The second is that this is one of the reaction products during the hot corrosion process and will be discussed in more details in the subsequent section.

\section{Oxidation}

Fig. 7 shows the surface morphologies of DA718 alloy after oxidation at $650 \square$ for $100 \mathrm{~h}$. After the alloy has been oxidized for $100 \mathrm{~h}$, concrete oxide layers had already formed on the surface of IN718 alloy. Most of the oxides were quite fine so that it was unable to clearly characterize them from such a high magnification. However, some white large oxide was observed and they were identified to be the oxide of $\mathrm{NbC}$ carbide. From the three dimensional image of the oxide scale shown in Fig. 7(b), the differences between grain boundary and inner grain were characterized. For the dark oxides within the inner grain, they seemed thicker than the oxide at grain boundaries. It has been reported that the oxidation behavior at intermediate temperature of IN718 alloy was controlled by the oxidation of $\mathrm{NbC}$ carbide and the formation of $\mathrm{Cr}_{2} \mathrm{O}_{3}$ and $\mathrm{Fe}_{2} \mathrm{O}_{3}$. [7, 8] The $\mathrm{Cr}_{2} \mathrm{O}_{3}$ would preferentially form at grain boundaries, which inhibits the progression of oxygen along grain boundaries. However, the $\mathrm{Cr}$ contents were not high enough to form continuous protective oxide layer at the initial oxidation stage, therefore other elements can be oxidized within the grain.
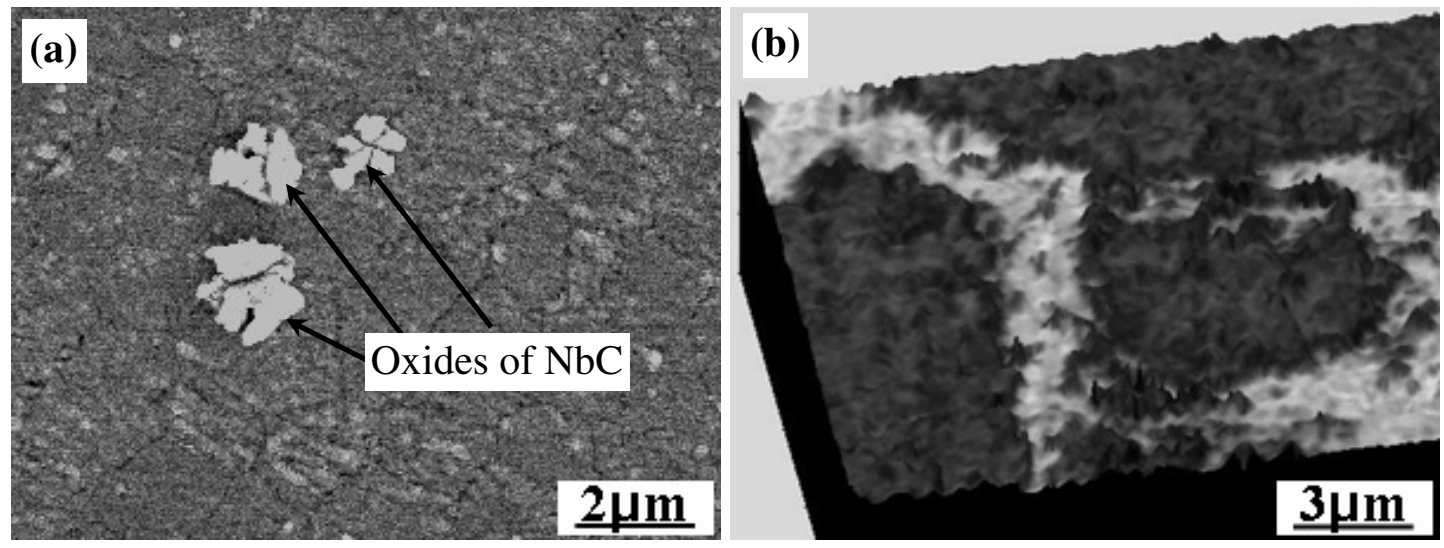

Fig. 7 Surface morphologies of DA718 alloy after oxidation at $650 \square$ for 100 h: (a) SEM image and (b) LSCM image

The creep curves of the aged sample and pre-oxidized sample are shown in Fig. 8. For 
pre-oxdized alloy 1 and aged alloy 1, the steady state creep curve shows a similar pattern and the creep rates are nearly identical. However, in the third stage of the creep curve, the preoxidized alloy 1 showed a higher creep rate, and the third creep stage was relatviely shorter. For high $\mathrm{P}$ doped alloy 2 , the preoxidation showed little effect on the creep curve and either the preoxidized alloy or the aged alloy showed a much longer creep life which is nearly four times of the low P-doped alloy 1 .
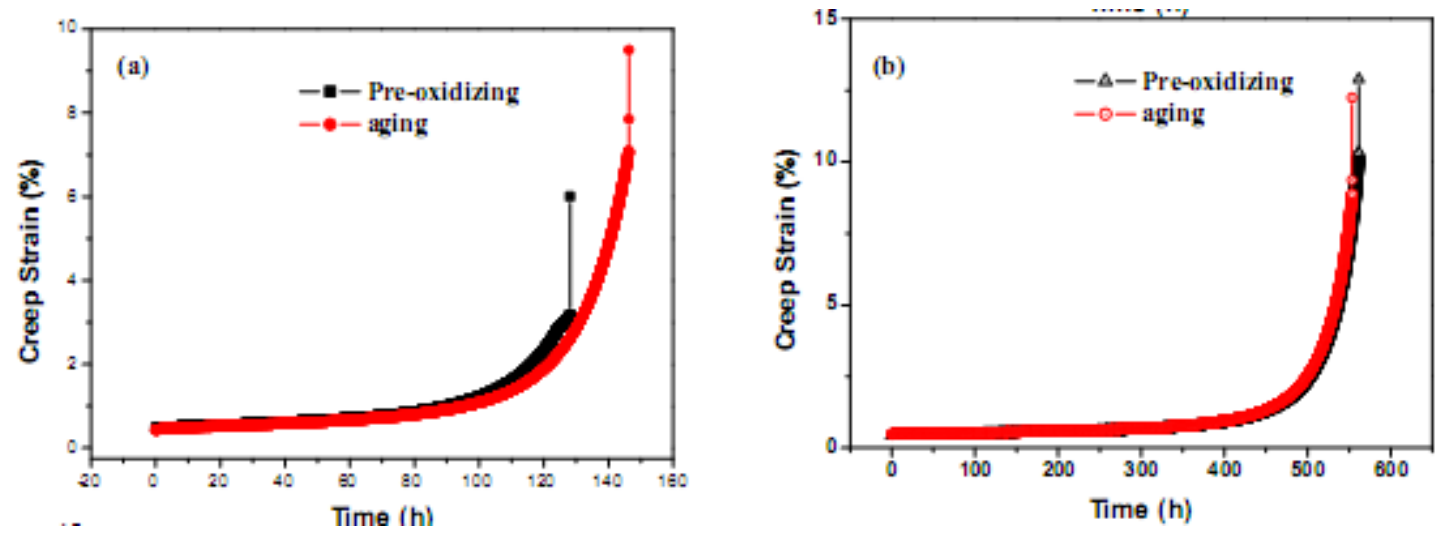

Fig. 8 Effect of pre-oxidation on the $650 \square / 725 \mathrm{MPa}$ creep property of (a) alloy 1 and (b) alloy $2(0.019 \% \mathrm{P})$

\section{Discussions}

The oxidation of metallic elements during hot corrosion

It has been well accepted that the following equilibriums exist in the melting of $\mathrm{Na}_{2} \mathrm{SO}_{4}[5,9$, $10]$.

$$
\begin{array}{r}
\mathrm{Na}_{2} \mathrm{SO}_{4} \rightarrow \mathrm{Na}_{2} \mathrm{O}+\mathrm{SO}_{3} \\
\mathrm{Na}_{2} \mathrm{SO}_{4} \rightarrow \mathrm{Na}_{2} \mathrm{~S}+2 \mathrm{O}_{2} \\
\mathrm{Na}_{2} \mathrm{~S}+2 \mathrm{O}_{2} \rightarrow \mathrm{Na}_{2} \mathrm{O}+\mathrm{SO}_{3}
\end{array}
$$




$$
\mathrm{Na}_{2} \mathrm{SO}_{4}(\mathrm{l}) \rightarrow 2 \mathrm{Na}^{+}+\mathrm{SO}_{3}+\mathrm{O}^{2-}
$$

The ionic dissociation of $\mathrm{Na}_{2} \mathrm{SO}_{4}$ (7) gives an important chemical equilibrium which is able to determine the acidity or the basicity of the molten $\mathrm{Na}_{2} \mathrm{SO}_{4}$. In the presence of melting $\mathrm{Na}_{2} \mathrm{SO}_{4}$, pure metals and alloys were simultaneously attacked by sulfur and oxygen, which in this case can be proved by the simultaneous formation of oxide and sulfide. It was suggested that the soluble oxidant in hot corrosion was $\mathrm{SO}_{3}\left(\mathrm{~S}_{2} \mathrm{O}_{7}^{2-}\right)$ in fused $\mathrm{Na}_{2} \mathrm{SO}_{4}[11,12]$. But the oxidation of $\mathrm{Cr}$ and $\mathrm{Fe}$ caused by $\mathrm{SO}_{3}$ should lead to the formation of chromium sulfide or iron sulfide, which were not detected in the scale. So the oxidant might be the oxygen dissolved in the melting salt or oxygen supplied by the dissociation of $\mathrm{Na}_{2} \mathrm{SO}_{4}$ according to Eq. (2). During the initial oxidation stage, $\mathrm{Cr}$ was selectively oxidized along the grain boundaries because of the high stability of $\mathrm{Cr}_{2} \mathrm{O}_{3}$, but $\mathrm{Ni}$ was not oxidized. The reason was related to the low partial pressure of oxygen in the atmosphere of melting salt, because the equilibrium oxygen partial pressure for the formation of $\mathrm{NiO}$ is much higher than $\mathrm{Cr}_{2} \mathrm{O}_{3}$. It must be pointed out that the amount of $\mathrm{Cr}$ in the alloy was not sufficient to cover the whole surface with continuous $\mathrm{Cr}_{2} \mathrm{O}_{3}$ layer. Because of that, the external layers of other oxides, $\mathrm{FeO}$ for example, and internal precipitates of $\mathrm{Cr}_{2} \mathrm{O}_{3}$ were formed on other areas of the alloy surface. In addition, because $\mathrm{Cr}_{2} \mathrm{O}_{3}$ was surrounded by $\mathrm{FeO}$ particles, the solid-state reaction occurred to form $\mathrm{FeCr}_{2} \mathrm{O}_{4}$ spinel in the scale, which gradually dispersed in external oxide layer. The chemical reaction describing this phenomenon can be written as follows:

$$
\mathrm{FeO}+\mathrm{Cr}_{2} \mathrm{O}_{3} \rightarrow \mathrm{FeCr}_{2} \mathrm{O}_{4}
$$

The product of the oxidation of $\mathrm{Fe}$ was not only $\mathrm{FeO}$ or $\mathrm{FeCr}_{2} \mathrm{O}_{4}$. With enough supply of oxygen, $\mathrm{Fe}_{2} \mathrm{O}_{3}$ spinel was also formed. The mechanism of iron oxide formation has been described in more detail by other researchers [13]. The growth of the spinel and $\mathrm{Cr}_{2} \mathrm{O}_{3}$ was controlled by the outward diffusion of both $\mathrm{Fe}$ and $\mathrm{Cr}$ due to a vacancy mechanism, requiring vacancy annihilation at sinks in the metal/scale interface [14]. With the oxidation process continuing through this outward diffusion, the surface was eventually completely covered with oxides. As the $\mathrm{Cr}$ and $\mathrm{Fe}$ 
oxides grew, the noble Ni component was repelled and then enriched at the alloy/scale interface. Later, a layer rich in $\mathrm{Ni}$ but depleted in $\mathrm{Cr}$ was formed as the subscale adjacent to the oxide layer. The consumption of oxygen caused by $\mathrm{Cr}, \mathrm{Fe}$ and other minor oxidizable elements decreased the oxygen activity, which increased the sulfur activity and accelerated the reduction of sulfur from $\mathrm{Na}_{2} \mathrm{SO}_{4}$. The oxidation of other minor elements, such as $\mathrm{Al}, \mathrm{Nb}$ and $\mathrm{Ti}$ will not be discussed here particularly even though they are very important affecting aspects of the hot corrosion process. The sulfidation of $\mathrm{Ni}$

It can be concluded that $\mathrm{Cr}$ and $\mathrm{Fe}$ were not directly involved in the sulfidation process by the fact that only nickel sulfide was formed during the hot corrosion process. As mentioned previously, while $\mathrm{Cr}$ was oxidized along the grain boundaries, the sulfidation of Ni happened simultaneously inside the grains. So the activity of both oxygen and sulfur can be extrapolated to be strong enough for the oxidation and sulfidation to take place at the alloy/melting salt interface at the initial stage of hot corrosion. The mechanism of the nickel sulfidation has been discussed by J.A. Goebel et al and the following reaction was achieved [5]:

$$
9 \mathrm{Ni}+2 \mathrm{SO}_{4}{ }^{2-} \rightarrow 6 \mathrm{NiO}+\mathrm{Ni}_{3} \mathrm{~S}_{2}+2 \mathrm{O}^{2-}
$$

The effect of twin boundaries needs to be mentioned here because twins always appear during the recrystallization process in IN718. The arrangement of atoms changes as twins are formed, and higher Gibbs-energy is expected at the twin boundary. It was easier for nickel sulfide to form at that point. Not only was $\mathrm{Ni}_{3} \mathrm{~S}_{2}$ formed in the hot corrosion process, but the eutectic $\mathrm{Ni}-\mathrm{Ni}_{3} \mathrm{~S}_{2}$ whose melting point was $645^{\circ} \mathrm{C}$, was also formed by the following reaction $[15,16]$ :

$$
\mathrm{Ni}+\mathrm{Ni}_{3} \mathrm{~S}_{2} \rightarrow \mathrm{Ni}-\mathrm{Ni}_{3} \mathrm{~S}_{2}
$$

When the surface of the alloy was totally covered by the oxide layer, both the oxygen activity and the sulfur activity at the interface would decrease from the initial level. Because of the existence of cracks or some other macro-defects in the oxide layers, the melting salt could permeate through the oxide layer. Or sulfur might diffuse from the $\mathrm{Na}_{2} \mathrm{SO}_{4}$ through the grain boundary or other micro-defects of the oxide layers to the alloy-oxide interface. Either way would supply sulfur to the substrate/scale interface, and the low oxygen activity at the interface could promote the sulfidation of Ni. In contrast to the formation of oxides, the nickel sulfidation process was controlled by the inward diffusion of $\mathrm{S}$ into the alloy, as shown in the previous section. The preferential diffusion path for sulfur was the grain boundaries of the alloy. Thus, the sulfur activity at the grain boundary increased rapidly during sulfur diffusion, and sulfide was formed there. It could be well proved by the existence of sulfide along the grain boundary adjacent to the subscale/substrate interface in this research. Similar results have also been achieved before by Zhu et al. [6]. However as shown in the results section, the depth of the sulfur 
penetration into the substrate was very limited, even less than the size of one grain, and nickel sulfide could also be observed inside the grains. This may be due to the fact that the rate of sulfur diffusion along the grain boundary was in the same order as its diffusion into the grains. Also in order for sulfur to diffuse it requires a high gradient of sulfur activity. When the grain boundaries were already occupied by continuous sulfides, the sulfur diffused from the subscale had to penetrate into grains.

The interaction between the oxidation $(\mathrm{Cr}, \mathrm{Fe})$ and sulfidation $(\mathrm{Ni})$ needs to be summarized in more detail. As stated before, the oxidation of $\mathrm{Cr}$, Fe and other minor oxidizable metallic elements decreased the activity of oxygen, and increased the sulfur activity in the melting salt. The diffusion rate of sulfur into the alloy was then accelerated. With the outward diffusion of $\mathrm{Cr}$ and $\mathrm{Fe}$ for the formation of oxides, a $\mathrm{Cr}$, Fe-depleted zone was formed beneath the oxide layer. This made the nickel more vulnerable to attacks by the sulfur. The formation of nickel sulfide, in return, accelerated the outward diffusion of $\mathrm{Cr}$ and Fe. First, the diffusion resistance of sulfides is very small because of the existence of multiple micro-defects [17]. Second, the reaction between $\mathrm{Ni}$ and $\mathrm{S}$ was exclusive, which repelled all other elements from the nickel sulfide layer and promoted the oxidation of the other elements.

There is no doubt that the removal of sulfur from $\mathrm{Na}_{2} \mathrm{SO}_{4}$ would cause the oxide ion activity to increase and then the oxide ions begin to react with oxide. Though no oxide ion activity data was collected in this research, it could also be deduced that the vicinity of the reaction (9) has the highest point of oxide ion activity and the reaction between $\mathrm{O}^{2-}$ and $\mathrm{NiO}$ was expected to occur there. Then $\mathrm{NiO}_{2}^{2-}$ diffused outside to the place where the $\mathrm{O}^{2-}$ activity was much lower and the dissociation reaction (12) was expected. The actual place of reaction (12) was not determined. Two possibilities were suggested. This could happen at the sulfide/oxide interface. Or $\mathrm{NiO}_{2}^{2-}$ could also diffuse into the fused salt and decompose, which could be confirmed only by knowing what the composition of the dark substance found at the crucible/salt interface was. More efforts will be implemented to clarify the hot corrosion mechanism of IN718 in the future.

$$
\begin{aligned}
& \mathrm{NiO}+\mathrm{O}^{2-} \rightarrow \mathrm{NiO}_{2}^{2-} \\
& \mathrm{NiO}_{2}^{2-} \rightarrow \mathrm{NiO}+\mathrm{O}^{2-}
\end{aligned}
$$

The effect of $\mathrm{P}$ on the sulfidation of grain boundaries

It is evident that phosphorus can inhibit the sulfidation of grain boundaries. Phosphorus has a strong tendency to segregate to the grain boundary and can increase the $\mathrm{MC}$ and $\mathrm{M}_{23} \mathrm{C}_{6}$ carbide intergranular precipitation [2]. It was shown earlier that the sulfide formed along grain boundaries was induced by the inward diffusion of sulfur. Competition of phosphorus with sulfur 
for sites in the grain boundaries is expected to take place. The presence of carbide precipitates along the grain boundaries would also hinder the diffusion of $\mathrm{S}$ deep into the material. The presence of phosphorus increases the hindering effect of carbides, so the diffusion of sulfur along grain boundaries was strongly suppressed.

The existence of attractive interactions between $\mathrm{P}$ and the metal elements of $\mathrm{Mo}$ and $\mathrm{Nb}$ was also obvious at the grain boundaries [18]. It was discussed that the reaction between $\mathrm{Ni}$ and $\mathrm{S}$ was exclusive and other elements must be repelled. Because of the co-segregation behavior of $\mathrm{P}$ and the metal elements along the grain boundaries, it would be hard for the metal elements to diffuse. Because of these aspects, the sulfidation of grain boundary was inhibited.

The effect of $\mathrm{P}$ on the intergranular oxidation

It can be inferred from Fig. 8(a) that the preoxidation did affect the creep properties of IN718 alloy, but the influence was limited, which only affects the third stage creep. While for high P-doped alloy 2 (Fig. 8(b)), the influence of preoxidation can be negligible. By comparision the influence intensity of preoxidation, it was believed that $\mathrm{P}$ did prevent the oxygen penetration along grain boundaries, but this influence was not the primary strengthening mechanism of $\mathrm{P}$ in IN718 alloy.

\section{Conclusions}

1.Both sulfide and oxides were formed during the initial stage of hot corrosion. After exposure for 200h, a scale with a multi-layered structure developed.

2.The outer oxide scales were mainly composed of $\mathrm{Fe}_{2} \mathrm{O}_{3}, \mathrm{FeCr}_{2} \mathrm{O}_{4}$, and $\mathrm{Cr}_{2} \mathrm{O}_{3}$. $\mathrm{NiO}$ was mixed with $\mathrm{Cr}_{2} \mathrm{O}_{3}$ between the external oxide layer and the subscale. The Ni-rich subscale consisted almost exclusively of $\mathrm{Ni}$ and $\mathrm{Ni}_{3} \mathrm{~S}_{2}$. The oxidation of $\mathrm{Cr}$ and $\mathrm{Fe}$ was controlled mainly by the outward diffusion of metallic atoms.

3.Nickel sulfide was formed by the inward diffusion of sulfur and was identified along grain-boundaries ahead of the subscale/substrate interface.

4.Phosphorus could inhibit the sulfidation of grain-boundaries by suppressing the inward diffusion of sulfur and the outward diffusion of metallic elements.

5.Phosphorus prevented the oxygen penetration along grain boundaries, but this influence was not the primary strengthening mechanism of P in IN718 alloy.

\section{References}

1. W. D. Cao and R. L. Kennedy, in:E.A.Loria(Ed.), Superalloys 718, 625 and Various

Derivatives, TMS-AIME, Warrendale, PA 1994, p.463-477.

2. C. G. McKamey, C. A. Camichael, W. D. Cao and R. L. Kennedy, Scripta Mater. 38 (1998) 485-491.

3. Hongwei Song, Shouren Guo and Zhuangqi Hu, Scripta Mater. 41 (1999) 215-219. 
4. W. R. Sun, et al., Mater.Sci.Eng. A247 (1998) 173-179.

5. J. A. Goebel, and F. S. Pettit, Metall. Trans. 4 (1970) 1943-1954.

6. Zhu Rizhang, Guo Manjiou, and Zuo Yu, Oxid. Met. 27 (1987) 253-265.

7. V. S. Babu, A. S. Pavlovic and M. S. Seehra. in:E.A.Loria(Ed.), Superalloys 718, 625, 706 and Various Derivatives, TMS-AIME, Warrendale, PA. 1991. 689-693.

8. T. Connolley, P. A. S. Reed and M. J. Starink. Mater. Sci. Eng. A. 2003 (340): 139-154.

9. R. Santorelli, E. Sivieri and R. Cristina Reggiani, Mater. Sci. and Eng. A120 (1989) 283-291.

10. C. A. C. Sequeira and M. G. Hocking, Br. Corros. J. 12 (1977) 158-162.

11. D.A. Shores, and W. C. Fang, J. Electrochem. Soc. 128 (1981) 346-348.

12. W. C. Fang, and R. A. Rapp, J. Electrochem. Soc. 130 (1983) 2335-2341.

13. R. Francis and D. G. Lees, Mater. Sci. and Eng. A120 (1989) 97-99.

14. Li Jian, C.Y.Yuh, and M.Farooque, Corros. Sci. 42 (2000) 1573-1585.

15. E. L. Simons, G. V. Browing, and H. A. Liebhafsky, Corr. 11 (1955) 505-514.

16. M. G. Hocking and V. Vasanthasree, Corros. Sci. 16 (1976) 279-295.

17. K. L. Luthra and W. L. Worrell, Metall. Trans. A9 (1978) 1055-1061.

18. Jianxin Dong, et al., Mater. Sci. Eng. A328 (2002) 8-13. 